\title{
SUBSTITUIÇÃO DA TORRE DE REFRIGERAÇÃO CONVENCIONAL POR EVAPORATIVE COOLER ${ }^{\star}$
}

Matheus de Aragão Togni ${ }^{1}$

\section{Resumo}

O processo de fabricação de gases do ar (oxigênio, nitrogênio e argônio) utiliza água como componente de resfriamento, para manter a temperatura do gás e dos equipamentos dentro dos limites operacionais. A qualidade de água está diretamente relacionada com a eficiência dos equipamentos rotativos, sendo assim quanto mais eficiente o sistema de resfriamento, menor será o impacto operacional, refletindo também no resultado financeiro da planta. Com o objetivo de melhorar o resultado operacional da unidade foi avaliada a troca do sistema de resfriamento convencional por um sistema com evaporative cooler.

Palavras-chave: Água de resfriamento; Troca de calor; Torre circuito fechado.

\section{COOLING WATER SYSTEM REPLACEMENT}

\begin{abstract}
The air separation process uses water to keep gas and equipment temperatures within operating limits. The water quality is directly related to rotating equipment efficiency, therefore an optimized cooling water system has a distinguished operational and financial impact on the process. In order to optimize cooling water system, it was proposed here and upgrade on it.
\end{abstract}

Keywords: Cooling water; Heat transfer; Evaporative cooler. 


\section{INTRODUÇÃO}

As unidades de produção auto-operada possuem em seu processo de especificação basicamente em as operações unitárias de admissão, purificação/adsorção e compressão de produto oxigênio ou nitrogênio.

No entanto para mantermos essas operações de compressão, purificação/adsorção precisamos de processos auxiliares que não estão conectados diretamente com os produtos, porém são essenciais para um bom desempenho. Um destes processos é o sistema de resfriamento que tem como objetivo manter as correntes de processo no patamar ideal para a operação e preservar os equipamentos.

Usualmente é utilizado as torres de resfriamento convencionais (Figura 1) para o sistema de refrigeração da planta, composto por uma bacia de água (responsável por manter um nível suficiente para as bombas que alimentam os trocadores de calor), recheios (proporciona a área de contato ar/água, onde ocorre dissipação do calor), distribuidor (projetado para dispersar a água igualmente em todo o recheio da torre para obter a maior área de troca térmica possível) e o ventilador (seu sentido de rotação é programado para retirar o ar de dentro da torre, assim realizando a reciclagem do ar interno succionando pelas aberturas laterais) .

Caso não haja tratamento adequado da água de resfriamento, a propriedade física de dureza tende a aumentar, deixando o sistema mais propício à calcificação e ocasionar o entupimento em alguns equipamentos da torre.

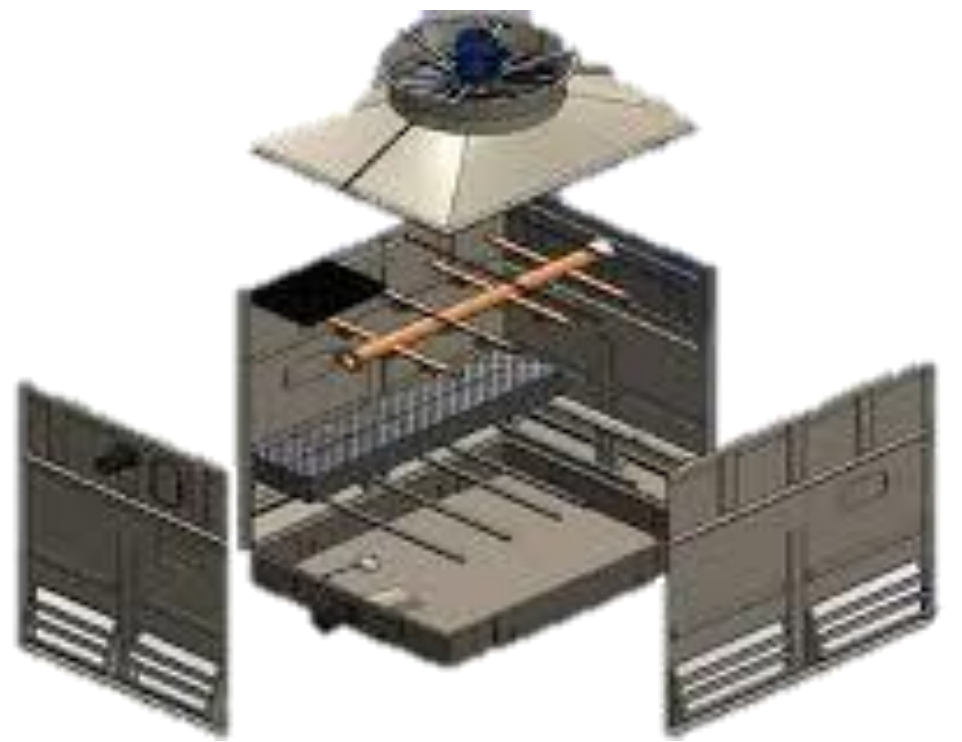

Figura 1: Torre de refrigeração convencional

Face as torre de resfriamento convencionais serem um sistema de contato direto e abertos a atmosfera, temos a influência do ambiente externo, podendo ser o ambiente corrosivo deteriorando o material da torre ou com particulado formando sedimentação e incrustações nos trocadores involuntariamente pelo sistema de água e prejudicam a performance das torres de resfriamento.

Esses produtos com o passar do tempo acabam ocasionando incrustações e sedimentando particulado por todo o sistema de água. Esses fatores prejudicam os distribuidores acumulando a sujeira nos mesmo e desequilibrando a distribuição de água, nos recheios ocorrem obstrução e formação de canais preferenciais, sendo a boa operação desses equipamentos fundamentais para um bom rendimento da torre. 
Para determinar o desempenho da torre de refrigeração em operação é utilizado o cálculo da diferença da temperatura da água de saída da torre e a temperatura de bulbo úmido do ar ambiente, os valores de approach normalmente encontrados estão entre $4^{\circ} \mathrm{C}$ e $10^{\circ} \mathrm{C}$, sempre buscando obter a menor diferença possível. Abaixo a representação do cálculo do approach (equação 1).

$$
\text { Approach }=T_{\text {Saída do Gás }}-T_{\text {Entrada da Água }}
$$

Tendo approach estabelecido, verificamos o delta de resfriamento que a torre irá exercer, sendo calculado através da diferença entre a temperatura da água de entrada da torre e a temperatura da água de saída da torre (equação 2).

$$
\Delta T_{\text {Resfriamento }}=T_{\text {Entrada Água na torre }}-T_{\text {Saída da Água na torre }}
$$

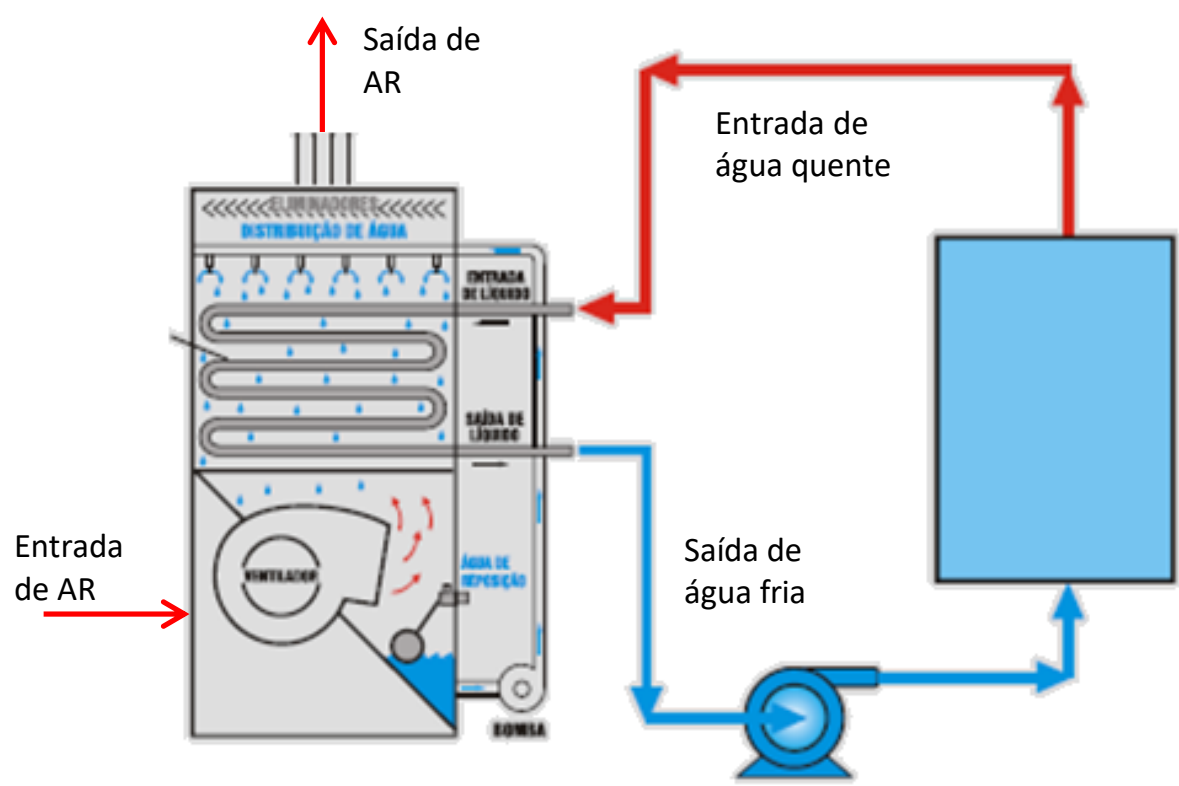

Figura 2: Representação do sistema de refrigeração

$\mathrm{Na}$ figura 2 temos uma representação da operação de um torre de resfriamento e suas correntes de processo.

A variação de temperatura encontrada é utilizada para encontrar a quantidade de calor a ser removida do sistema através da equação de taxa de transferência de calor, representado abaixo pela equação 3 .

Sendo:

$$
\boldsymbol{Q}=\boldsymbol{m} * \boldsymbol{C} \boldsymbol{p} * \Delta \boldsymbol{T}
$$

$\mathrm{m}$, a vazão mássica da água de recirculação [kg]

Cp, o calor específico a pressão constante do fluído [J/kg K]

$\Delta \mathrm{T}$, diferença de temperatura entre a entrada e saída do processo $[\mathrm{K}]$

O valor da energia resultante da equação de transferência de calor determinará o dimensionamento do evaporative e consequentemente o modelo do mesmo. 
Temos como objetivo melhorar o sistema de refrigeração da unidade de maneira a reduzirmos a temperatura de água fria e evitar o desarme da planta por alta temperatura no processo.

\section{MATERIAIS E MÉTODOS}

$\mathrm{Na}$ Tabela 1, é referenciado o histórico de approach de outras unidades de produção de gases e da unidade a qual foi instalado o evaporative cooler.

Tabela 1: Approach das usinas da região.

\begin{tabular}{|c|c|c|}
\hline Usina & \multicolumn{2}{|c|}{ Approach } \\
\hline Referência 1 & 6 & $\stackrel{\circ}{ } \mathrm{C}$ \\
\hline Referência 2 & 7 & $\stackrel{\circ}{ } \mathrm{C}$ \\
\hline Referência 3 & 10 & $\stackrel{\circ}{ } \mathrm{C}$ \\
\hline Referência 4 & 7 & $\stackrel{\circ}{ }$ \\
\hline Referência 5 & 8 & 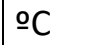 \\
\hline Projeto & 7 & $\stackrel{\circ}{ } \mathrm{C}$ \\
\hline
\end{tabular}

O approach das torres de refrigeração para processos industriais ficam em torno de $5^{\circ} \mathrm{C}$ conforme dados dos fabricantes do equipamento, comparando com os valores da Tabela 1, identifica-se que as torres existentes estão com performance próxima aos dados de seus fabricantes, porém mostra que há possibilidade de melhora no sistema. Face a está oportunidade, buscou-se um novo equipamento o qual tenha capacidade térmica de atingir os $5^{\circ} \mathrm{C}$ de approach informado pelos fabricantes, assim foi apresentado um equipamento com dimensões superiores ao existente.

Além da oportunidade de melhorar o desempenho do sistema de refrigeração, verificou-se que havia oportunidade de melhorar a qualidade da água circulante no sistema, fato que o sistema da torre de refrigeração convencional ser aberto o mesmo está propício a gerar sedimentos e incrustações.

Sendo assim, o projeto concebeu-se com a substituição da torre de refrigeração convencional de sistema aberto por um sistema de circuito fechado (evaporative cooler), assim projetando um equipamento de melhor desempenho para evitar paradas por alta temperatura no processo e reduzir o número de intervenções nos trocadores de calor.

O evaporative cooler, apresentado abaixo na Figura 3, tem seu modo de operação semelhando ao da torre de resfriamento convencional, sendo sua principal diferença o sistema interno do equipamento, que consiste em serpentinas que percorrem todo o interior do equipamento circulando a água à ser refrigerada, sendo assim a água não entra em contato com o meio externo, não havendo a mudança de fase da água não temos a alteração das, evitando a contaminação com sujeiras e particulados, consequentemente reduzindo as incrustações e sedimentações. 

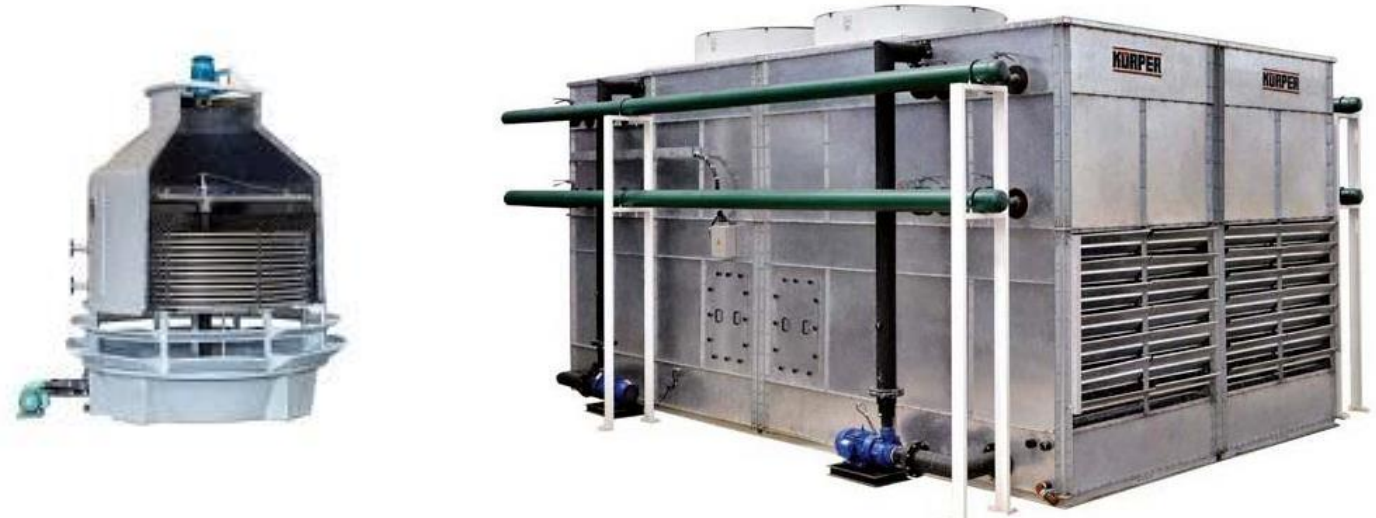

Figura 3: Torre de refrigeração sistema fechado (evaporative cooler)

Devido à água não entrar em contato direto com o ar que o resfria, 0 equipamento possuí uma eficiência menor que as torres convencionais e para que se obtenha a mesma taxa de refrigeração precisamos de uma área de troca térmica maior, consequentemente o equipamento será maior. Para determinar a nova área de troca térmica utilizamos a equação da primeira lei da termodinâmica (equação 4).

Sendo:

$$
\boldsymbol{A}=\frac{\boldsymbol{Q}}{\boldsymbol{U} * \boldsymbol{L M T D}}
$$

A, a área de Troca de Calor [ $\left.\mathrm{m}^{2}\right]$

$\mathrm{Q}$, o calor Trocado no Sistema [W]

$\mathrm{U}$, o coeficiente global de transferência de calor $\left[\mathrm{W} / \mathrm{m}^{2} \mathrm{~K}\right]$

LMTD, a diferença de temperatura média logarítmica $[K]$

Fato a água não ter contato com a atmosfera, os sedimentos e incrustações nos trocadores de calor reduziram, assim obtendo melhorara na performance nestes equipamentos, evitando a elevação da temperatura do processo e consequentemente reduzindo o número de paradas por alta temperatura no processo.

\section{RESULTADOS E DISCUSSÃO}

Podemos observar que os números de ocorrências de paradas por alta temperatura são elevados, sendo o maior valor dentro todas variáveis da operação, conforme apresentado os dados do primeiro trimestre de 2016 no gráfico 1 .

O equipamento entrou em operação no mês de dezembro de 2016, apresenta-se no gráfico 1 uma comparação entre o primeiro trimestre de $2016 \mathrm{com}$ o primeiro trimestre de 2017 , onde após o inicio de operação não houve mais nenhuma ocorrência por temperatura. 
\% № de Ocorrências por Variável

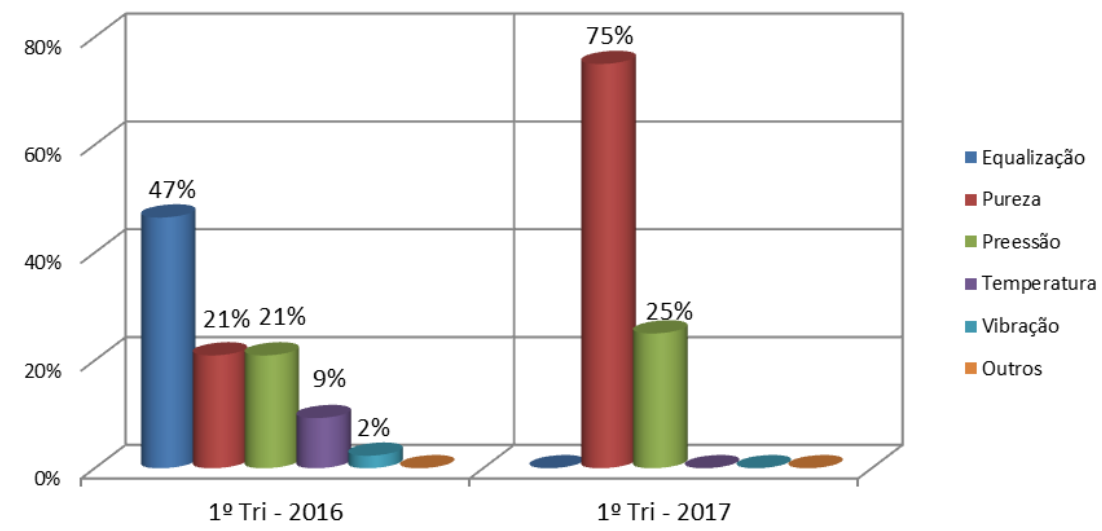

Gráfico 1: Comparativo de ocorrências por variável [\%]

O $\Delta$ Resfriamento da água aumentou em 4 vezes após a partida do novo equipamento, conforme representado no eixo da direita do Gráfico 2, essa otimização de resfriamento da água impactou em todas as demais temperaturas de operação da unidade, obtendo maior eficiência no processo de compressão, purificação/adsorção.

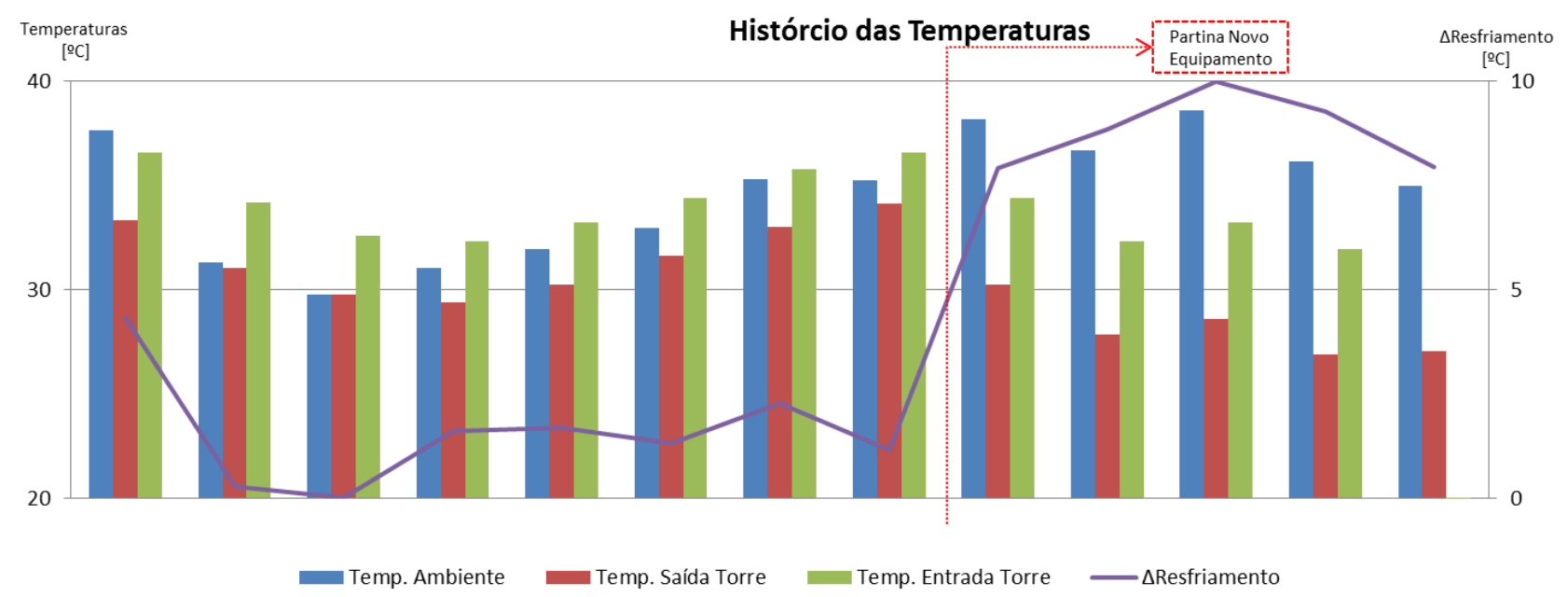

Gráfico 2: Histórico das temperaturas e $\Delta$ Resfriamento $\left[{ }^{\circ} \mathrm{C}\right]$

\section{CONCLUSÃO}

O objetivo deste trabalho foi alcançado, onde ocorreu a redução significativa na temperatura de água fria que alimenta o processo aumentando a confiabilidade do sistema e eliminando as paradas do processo por alta temperatura e outro benefício obtido será a redução de incrustação do sistema face ao sistema de água ser em circuito fechado sem contato com o meio externo. Assim, reduzindo a quantidade de intervenções para limpeza dos trocadores de calor, consequentemente reduzindo os custos de mão de obra e material para uma tarefa essa atividade.

\section{Agradecimentos}


Nossos agradecimentos vão para toda a equipe da manutenção da região de Americana, Rogério Marineli, Edemilson Zanuncio, Angelo Galani e Roldao Bandeira, que se comprometeram com a execução e comissionamento do projeto desde o início.

\section{REFERÊNCIAS}

1 - SMITH, J. M.; VAN NESS, H. C. Introduction to Chemical Engineerging Thermodynamics. 7 ed. Nova York: McGraw-Hill. 1959. 697 p

2 - PERRY, R. H.,; Green, D. W. Perry's Chemical Engineers' Handbook. 8 ed Nova York: McGraw-Hill. 2008. $2851 \mathrm{p}$

3 - KREITH, F.; "Princípios da Transmissão de Calor", Edit. Edgard Blücher Ltda.1977 